\title{
LETTERS
}

\section{Losing doctors with integrity will harm patients and profession}

I am responding to a letter by Dr. Eric Brown $^{1}$ about semantics in referring for medical assistance in dying (MAiD). It is true, as he stated, that "The religious rights of all Canadians are protected, but the right to a particular occupation is not." The intended implication, it seems, is that any conscientious objectors should simply leave the practice of medicine. This is a common argument levelled against conscientious objectors. However, there are several problems with this argument, and I would like to highlight two.

First, it is worth keeping at the forefront that, as Dr. Diane Kelsall pointed out in her editorial, ${ }^{2}$ any kind of participation in MAiD would have been judged as culpable homicide until 2015. If Dr. Brown's argument is taken to its logical conclusion, what would it mean for the many physicians who entered practice before that time with both a legal and a personal moral responsibility not to end the lives of their patients intentionally? It certainly is not that they knew what they were getting into and, therefore, have no excuse for refusing to perform a service that is part of the job. Instead, it seems as though this line of reasoning would force many competent, compassionate and well-intentioned physicians out of a profession that they entered in good faith. This is a loss for both patients and the medical profession.

Second, I would like to point out that Dr. Brown's line of reasoning will result in depriving patients of access to many physicians with a crucial quality: integrity. It is not for nothing that the new Canadian Medical Association Code of Ethics, which is currently under review, states that integrity is one of the "virtues exemplified by the ethical physician" (www.cma.ca/Assets/ assets-library/document/en/advocacy/cma -code-of-ethics-e.pdf). I am not suggesting that those physicians who provide MAiD lack integrity, but it is important to consider the implications of Dr. Brown's argument. If his line of reasoning is followed to its logical conclusion, the only physicians who would be allowed to practise medicine would be those who conformed when it came to ethical issues, even if they felt personally uncomfortable; in other words, physicians without integrity. This is a loss for patients.

Moreover, it is not too difficult to think of times when there was a broad acceptance in the medical community of practices that we now find objectionable. The Tuskegee Syphilis Study or involuntary sterilizations during the eugenics movement in the early 20th century come to mind. I do not intend to compare these events with the provision of MAiD but only wish to point out the following: if we allow only physicians who disregard their personal convictions and conform to practise medicine, how will we ever make ethical progress as a profession? The loss of physicians with integrity will harm both patients and the medical profession.

Given these flaws and that Ontario is one of, if not the only, jurisdiction in the world that mandates that physicians make such a direct referral, is this really necessary? As with Dr. Kelsall, I believe that there is surely another way forward!

\section{Karol F. Boschung}

MD candidate, class of 2021, Faculty of Medicine, University of British Columbia, Vancouver, BC

Cite as: CMAJ 2018 November 5;190: E1310. doi: $10.1503 / \mathrm{cmaj} .70444$

\section{References}

1. Brown E. Semantics in referring for medical assistance in dying [letter]. CMAJ 2018;190:E692.

2. Kelsall D. Physicians are not solely responsible for ensuring access to medical assistance in dying. CMAJ 2018;190:E181.

Competing interests: None declared. 